Accepted for publication in "Cognitive Therapy and Research". Note: This is an uncorrected version of an author's manuscript accepted for publication. Copyediting, typesetting, and review of the resulting proofs will be undertaken on this manuscript before final publication. During production and pre-press, errors may be discovered that could affect the content.

\title{
The Brief State Rumination Inventory (BSRI): Validation and Psychometric Evaluation
}

\author{
Igor Marchetti $^{1,}{ }^{*}$, Nilly Mor ${ }^{2}$, Carlo Chiorri ${ }^{3}$, \& Ernst H. W. Koster ${ }^{1}$ \\ ${ }^{1}$ Ghent University, Belgium \\ ${ }^{2}$ Hebrew University of Jerusalem, Israel \\ ${ }^{3}$ University of Genoa, Italy
}

\begin{abstract}
Author Note
This research was funded in part by the Research Foundation Flanders, which supports Igor Marchetti as postdoctoral research fellow (FWO14/PDO/115). Nilly Mor is support by the Israel Science Foundation (ISF 1519/13). The authors have no competing interests in this research. The authors thank Noa Avirbach, Tal Ganor, and Baruch Perlman for their assistance in the item development process.

${ }^{\mathrm{a} C}$ Corresponding author. Igor Marchetti, Ghent University, Department of Experimental-Clinical and Health Psychology, Henri Dunantlaan 2, 9000 Ghent (Belgium); Email: igor.marchetti@ugent.be.
\end{abstract}




\begin{abstract}
Depressive rumination is an emotion regulation strategy that is considered a major risk factor for depression and other emotional disorders. While well-established measures of trait rumination are available, a psychometrically sound measure of state rumination is lacking. We report on the development and validation of a new self-report measure, the Brief State Rumination Inventory (BSRI), in both Dutch and English. In Study 1, we report the results of a multi-group confirmatory factor analysis across three independent samples $(n=155 ; n=141$; $\mathrm{n}=199$ ). The analysis supported the unidimensionality and measurement invariance of the 8item BSRI. We also examined its construct validity, showing that scores on the BSRI were positively related to measures of negative affect, trait rumination, and symptoms of depression and anxiety. Scores were negatively related to adaptive emotion regulation strategies and to positive affect. In Study $2(\mathrm{n}=60)$, we demonstrated the measure's sensitivity to an experimental manipulation of rumination. Taken together, these findings suggest that the BSRI is a quick-to-administer, valid, and reliable measure of state rumination.
\end{abstract}

Keywords: rumination, state measure, questionnaire, BSRI 
Depressive rumination is a particularly maladaptive form of self-focus (Mor \& Winquist, 2002; Nolen-Hoeksema, Wisco, \& Lyubomirsky, 2008), which involves repetitively focusing attention on the causes and implications of one's negative mood (Nolen-Hoeksema, 1991). Rather than leading to improved self-understanding or problem solving, depressive rumination augments sad mood and negative thinking (Lyubomirsky \& Nolen-Hoeksema, 1995). Rumination is associated with significant negative consequences, such as increased risk for a depressive onset (e.g., Nolen-Hoeksema, 2000; Nolen-Hoeksema, Parker, \& Larson, 1994) and prolonged depression (Kuehner \& Weber, 1999; Nolen-Hoeksema, Morrow, \& Fredrickson, 1993). Rumination also contributes to other psychiatric conditions including anxiety disorders, substance abuse, and bulimic behavior (Kocovski, Endler, Rector, \& Flett, 2005; NolenHoeksema, Stice, Wade, \& Bohon, 2007).

Rumination has been considered as both a state response to negative mood (Martin \& Tesser, 1996) and a habitual tendency to engage in repetitive and passive self-focus in response to depressed mood (Nolen-Hoeksema et al., 2008). Nolen-Hoeksema's seminal work has demonstrated that individuals show stable, trait-like responses to negative mood states (for a review, Lyubomirsky, Layous, Chancellor, \& Nelson, 2015). Accordingly, several questionnaires have been developed to measure trait rumination. The most commonly used scale is the Ruminative Response Scale (RRS; Nolen-Hoeksema \& Morrow, 1991), which assesses two typical responses to sad mood, namely brooding and reflection (Treynor, Gonzalez, \& Nolen-Hoeksema, 2003). Brooding denotes the degree to which individuals passively focus on symptoms of distress and on the meaning of these symptoms, whereas reflection is characterized by purposefully turning inward to engage in problem solving to improve negative mood. In addition, a variety of self-report questionnaires assess trait rumination as a transdiagnostic mechanism by primarily focusing on its repetitive and perseverative nature. These include the Rumination-Reflection Questionnaire (RRQ; Trapnell 
\& Campbell, 1999), the Repetitive Thinking Questionnaire (RTQ; Mahoney, McEvoy, \& Moulds, 2012), and the Perseverative Thinking Questionnaire (PTQ; Ehring et al., 2011).

Alternatively, rumination has been viewed as a state episode or a temporary cognitive response that is highly dependent on situational cues and may be triggered by momentary perceived discrepancies between one's goals and current state (for reviews, see Martin \& Tesser, 1996; Smith \& Alloy, 2009; Watkins \& Nolen-Hoeksema, 2014). The effects of state rumination have been examined in numerous lab-based studies, which found negative effects on mood, thought processes, problem solving, goal-oriented behavior, and psychopathology (for a review, see Lyubomirsky et al., 2015). Moreover, confirming its momentary nature, state rumination appears to fluctuate over the day, with a decrease at midday and an increase in the morning and evening (Moberly \& Watkins, 2008; Takano \& Tanno, 2011).

From a theoretical standpoint, personality theories argue that self-reported traits do not merely represent the aggregation of moments or states (e.g., Augustine \& Larsen, 2012; McCabe \& Fleeson, 2016), in that people rely on different types of information when reporting on states rather than traits (Robinson \& Clore, 2002). In keeping with this, meaningful differences between trait and state rumination have been reported. For instance, state rumination predicts subsequent negative affect, poor recovery from sad mood, and emotional reactivity to a social stressor, independently of trait rumination (Hilt, Aldao, \& Fischer, 2015; LeMoult, Arditte, D'Avanzato, \& Joormann, 2013; Moberly \& Watkins, 2008). Taken together, these findings suggest that state rumination is a highly informative phenomenon for mental functioning, whose very features are not fully captured by trait rumination.

Despite the increased interest in state rumination, a psychometrically sound measure that can assess fluctuations in ruminative responses in reaction to negative mood, has not been developed yet. A variety of measures address specific forms of state rumination, such as following an interpersonal offense (McCullough, Bono, \& Root, 2007) or an intelligence test 
(LeMoult et al., 2013), with their limited scope making them unsuitable as a measure of state rumination in other contexts. Some measures have adopted a time reference incompatible with a state assessment (e.g., a span of an hour or a day; Ciesla, Reilly, Dickson, Emanuel, \& Updegraff, 2012; Hilt et. al., 2015), or they capture multiple facets at the same time, such as neutral self-focus and ruminative thoughts (Marchetti, Koster, \& De Raedt, 2013). Other studies evaluated state rumination in the context of experience sampling using either a single item or a composite of items with no rationale for their clustering (e.g., Genet \& Siemer, 2012; Mor et al., 2010; Roberts, Watkins, \& Wills, 2013; Takano \& Tanno, 2011). Finally, although a recent measure was designed specifically to assess state emotion regulation and includes a brooding subscale (Katz, Lustig, Assis, \& Yovel, 2017), this scale requires an elicitation of a negative thought followed by a waiting period as well as the administration of additional subscales assessing acceptance, distraction and reappraisal, all of which may not be appropriate in some research.

It is also critical to note that in most cases these measures did not undergo a thorough validation process. Typically, studies are only informative about the scale's reliability (i.e., Cronbach's alpha) rather than its dimensionality (i.e., factor analysis). This is particularly worrisome, as it has been abundantly shown that a multidimensional test does not necessarily have a lower reliability than a unidimensional test (Tavakol \& Dennick, 2011). Information about the measures' concurrent, discriminant, and criterion validity is usually lacking.

In sum, there is currently no measure for state rumination with strong internal validity and solid psychometric properties. To fill this gap, the aim of the current research was to develop a brief self-report measure with robust psychometric properties, which could be used in the lab setting as well as in ambulatory assessment. We report below the development and validation process of the Brief State Rumination Inventory (BSRI) and two studies that examined its underlying unidimensionality, reliability, and validity. In order to build a measure 
that could be used in a variety of settings and facilitate its dissemination, we developed the BSRI in both Dutch and English, and we made it suitable for paper-and-pencil as well as online administration. All studies were approved by the Ethical Committee of the Faculty of Psychology and Educational Science of Ghent University.

\section{Scale Development}

In developing the BSRI we focused on maladaptive aspects of ruminative thinking. Items were created to capture maladaptive state rumination defined as the momentary occurrence of thoughts that focus one's attention on one's distress along with its possible causes and implications (Nolen-Hoeksema et al., 2008). Accordingly, the items were designed to assess repetitive negative thoughts at the time of answering ("Please respond to the following items by referring to the way you feel or think right now. For each item, please mark a vertical line on the horizontal line to indicate the degree to which you agree or disagree with the statement").

Each item lies on a 100-mm visual analogue scale (VAS) ranging from "completely disagree" to "completely agree". The VAS response format has become increasingly popular when measuring dynamic subjective states that may change swiftly and/or whose repeated assessment can be burdensome (Abend, Dan, Maoz, Raz, \& Bar-Haim, 2014). VAS scales have proved to have similar psychometric properties to (Rossi \& Pourtois, 2012) and sometimes better (Du Troit, Pritchard, Heffernan, Simpson, \& Fonn, 2002) than Likert-based scales. Moreover, VAS scales can be easily integrated in computer-based applications and computerized experiments, which facilitates data collection and increases responder's compliance (Ryan, Corry, Attewell, \& Smithson, 2002; Stone, Shiffman, Schwartz, Broderick, \& Hufford, 2002).

Initially, we developed a pool of thirteen items based on the definition reported above, by reviewing well-established measures of trait rumination (RRS, PTQ, RTQ, and RRQ) and adapting the items for the BSRI. We relied on several trait measures for both theoretical and 
practical reasons. From the theoretical standpoint, although trait rumination has increasingly grown into a multifaceted construct (e.g., brooding, preservative thought, repetitive negative thinking), such differentiations do not necessarily extend to state rumination. Previous research on personality factors showed that well-established construct facets at trait level (i.e., Big Five factor solutions) may be blurred at state level (i.e., Borkenau \& Ostendorf, 1998; Molenaar, 2004). Hence, it would be premature to assume that state rumination shows the same variety of features as trait rumination does. From a practical standpoint, each scale measuring rumination included items that were not modifiable to fit a state questionnaire that can be used in a lab setting (e.g., "Go someplace alone to think about your feelings"; RRS). The items were then translated and back translated from English to Dutch with the intention to provide a short unidimensional measure of maladaptive ruminative thinking.

In order to test their content validity, the items were administered to a small sample of experts in rumination research $(n=9)$, who evaluated the relevance and representativeness of the items to the above definition of rumination on a 3-point ordinal scale. All items received a median score of at least 2 on both dimensions and were deemed adequately relevant and representative. Therefore all the initial items were retained for the subsequent validation procedure.

\section{Study 1}

In Study 1, we aimed to test the factor structure of the initial item pool on three independent samples in a simultaneous fashion using multi-group confirmatory factor analysis (MG-CFA; Jöreskog, 1971). This approach allowed us (i) to test for the replicability and the generalizability of the factor structure of the new measure, and (ii) to test for the measurement invariance of the new measure, i.e., whether the scale measure the same construct in the same way in all samples. 
We also examined the convergent and discriminant validity of the BSRI by exploring its association with other constructs lying in the same nomological network (in samples 2 and 3). Specifically, we predicted a positive but moderate correlation between scores on the BSRI and rumination subtypes, namely brooding and reflection (Treynor et al., 2003). We further predicted that state rumination would be positively linked to symptoms of depression, anxiety, stress, and concurrent negative mood, but negatively related to positive mood (NolenHoeksema et al., 2008). Finally, we expected that state rumination would be significantly related to major emotion regulation strategies. Mirroring the pattern of associations of trait rumination, we predicted that state rumination would be positively related to suppression (Gross \& John, 2003), and negatively associated with helpful forms of emotion regulation, such as reappraisal (D’Avanzanto, Joormann, Siemer, \& Gotlib, 2013) and mindfulness (Chambers, Lo, \& Allen, 2008; Gross \& John, 2003). Because the RRS subscales and the BSRI both assess ruminative thinking (albeit different forms of such thinking), we reasoned that correlations of the BSRI with the RRS subscales would be higher than its correlations with the other measures.

\section{Method}

\section{Participants and Procedure.}

Sample 1 comprised 155 volunteers (females: 95\%; mean age $21.84 \pm 1.45$ years; range: 20-28) and sample 2 comprised another 141 volunteers (females: $85 \%$; mean age $20.71 \pm 1.44$ years; range: 19-26). Both samples consisted of Dutch-speaking undergraduate students enrolled in psychology courses at a Belgian university. No specific inclusion or exclusion criteria were applied. Participants completed a paper-and-pencil version of the measures administered and received course credit for their participation.

Sample 3 comprised 199 English-speaking individuals (females: 48\%; mean age 29.82 \pm 7.62 years; range: 18-53) from the US, recruited online via the Prolific Academic platform (http://www.prolific.ac), which has been proved to provide high-quality data (Peer, Brandimarte, 
Samat, \& Acquisti, 2017). They completed an online version of the battery of questionnaires described in the Measures section and received $2 \$$ for their participation.

\section{Measures.}

All the measures were language-consistent within each administration, namely either Dutch (sample 1 and 2) or English (sample 3). In sample 1, only information about state rumination was acquired (i.e., BSRI items), whereas in samples 2 and 3 all the measures reported below were administered.

Brief State Rumination Inventory (BSRI). See above.

Ruminative Responses Scale (RRS; Treynor et al., 2003). Trait rumination was assessed using the two 5-item subscales (brooding and reflection) of the RRS. Participants were asked to rate the frequency with which they respond to negative mood as described in each item using a 4-point Likert-type scale, ranging from 1 (almost never) to 4 (almost always). Internal consistency of the brooding and reflection subscales in sample 2 was .72 and .69 , respectively, and in sample 3 it was .85 and .81 , respectively.

Depression Anxiety Stress Scales - 21 (DASS-21; Henry \& Crawford, 2005). The DASS-21 is a 21-item self-report questionnaire assessing the presence of symptoms related to the depressive, anxious, or stress-related spectrum. It consists of three 7-item subscales, and items were rated on a 4-point, Likert-type, frequency scale, ranging from 1 (never) to 4 (always). Internal consistency of the three subscales in sample 2 was .88 for depression, .79 for anxiety and .88 for stress, and in sample 3 it was .92 for depression, .85 for anxiety and .87 for stress.

Positive and Negative Affect Schedule (PANAS; Watson, Clark, \& Tellegen, 1988). We administered the PANAS to measure affective style. This is a 20 -item questionnaire assessing both positive and negative trait affectivity. Items are adjectives that describe different emotional states, and participants were asked to rate the degree to which they generally feel the 
emotional state described in each item, on a 5-point, Likert-type, intensity scale, ranging from 1 (very slightly or not at all) to 5 (extremely). Internal consistency of the positive and negative affect subscales in sample 2 was .82 and .84 , respectively, while in sample 3 it was .93 and .93 , respectively.

Emotion Regulation Questionnaire (ERQ; Gross \& John, 2003). The ERQ measures habitual use of two emotion regulation strategies, cognitive reappraisal and suppression. Reappraisal refers to changing the way a situation is construed to decrease its negative emotional impact. In contrast, suppression is defined as a voluntary effort to inhibit emotional expressive behavior (Gross, 1998). Whereas reappraisal is considered an adaptive emotion regulation strategy, suppression is not (Gross \& John, 2003). The two strategies were measured by 4 and 6 items, respectively, rated on a 7-point, Likert-type, agreement scale, ranging from 1 (completely disagree) to 7 (completely agree). Internal consistency of the suppression and reappraisal subscales in sample 2 was .81 and .78 , respectively, and.92 and .81 , respectively, in sample 3.

Mindful Attention Awareness Scale (MAAS; Brown \& Ryan, 2003). The MAAS is a 15-item self-report questionnaire that assesses individual differences in the frequency of mindful states over time. Items on the MAAS assess attention to and awareness of what is occurring in the present and are rated on a 6-point, Likert-type frequency scale, ranging from 1 (almost always) to 6 (almost never). Higher scores imply higher levels of trait mindfulness. Internal consistency of the MAAS was .83 in sample 2 and .92 in sample 3.

\section{Data analysis strategy and preliminary analyses}

Using a scree-plot test and parallel analysis (Horn, 1965), we initially tested whether the same number of factors accounts for the correlations among BSRI items across the samples. As shown in Figure S1, the observed eigenvalues flattened out from the second factor, and only the first observed eigenvalue was larger than the 95th percentile of the distribution of the 
simulated random eigenvalues (i.e., parallel analysis). These preliminary analyses suggested that a one-factor structure could be an adequate measurement model for the BSRI items in all samples.

When developing a new measure, exploratory factor analysis (EFA) is often conducted as a first step. However, because the dimensional analyses supported our prediction of a unidimensional structure, we directly tested the factor structure of the BSRI initial item pool using a confirmatory approach, which has the advantage of providing parameter estimates, standard errors, goodness-of-fit statistics, and modification indices that can help in scale refinement ${ }^{1}$.

In order to test whether our smallest sample (sample $2, n=141$ ) provided sufficient statistical power to adequately estimate all the model parameters and their standard errors in a CFA model, we performed a Monte Carlo analysis as described in Muthen and Muthen (2002) 2 . In order to show power close to 0.80 , the authors suggest considering that (1) parameter and standard error biases do not exceed $10 \%$ for any parameter in the model (in our sample $1.73 \%$ ); (2) the standard error bias for the factor loadings and error variances does not exceed 5\% (in our sample $2.12 \%$ ); (3) the proportion of estimates' confidence intervals that include the true parameter is between .91 and .98 (in our sample .928 to .950 ). Because these three conditions were satisfied, our smallest sample size was considered satisfactory (Muthén \& Muthén ,2002)

Factor structure and measurement invariance was tested in accordance to Meredith (1993). We began with testing factor structure invariance (i.e., configural invariance), whose main requirement is that the same items are indicators of the same latent factor in each sample. In this type of invariance model, all parameters are freely estimated and no invariance constraints are imposed, but the same confirmatory factor analysis must hold in each sample.

The test of factor structure invariance models was followed by a test of weak invariance, which constrains factor loadings to be invariant over samples. If identical items have 
statistically equivalent loadings, then the scores of identical items show the same amount of increase between samples for the same amount of increase on the latent factor (i.e., equality of scaling units). For the purposes of this paper, evidence of weak invariance is considered as a satisfactory result, as it would imply that respondents across groups attributed the same meaning to the latent construct under study. For sake of completeness, we also investigated strong invariance (i.e., equivalent item intercepts) and strict invariance (i.e., equivalent item errors) (Meredith, 1993) (see Supplementary Material).

Following Hau, Marsh, and Wen (2004), model fit was evaluated using the comparative fit index (CFI), the Tucker-Lewis index (TLI), and the Root Mean Square Error of Approximation (RMSEA). TLI and CFI values greater than .90 and .95 and RMSEA values lower than .08 and .06 were taken to reflect acceptable and excellent fit to the data, respectively. While comparing nested invariance models, our evaluation criteria were based on guidelines derived from methodological research (Cheung \& Rensvold, 2001; Chen, 2007). In detail, we considered support for the more parsimonious model to be evidenced in a change from the less parsimonious model in the CFI of less than .01 (Chen, 2007; Cheung \& Rensvold, 2001) or a change in the RMSEA of less than .015 (Chen, 2007). In this case, we avoided relying on chisquare tests since these tests suffer the same problems (i.e., being too liberal in rejecting the model with relatively large samples) as the chi-square test used to test goodness of fit that led to the development of fit indices (see Marsh, Hau, Balla, \& Grayson, 1998).

To examine the construct validity of the BSRI, we conducted a test of the heterogeneity of dependent correlation coefficients (Meng, Rosenthal, \& Rubin, 1992) using data from samples 2 and 3. As we also expected that the BSRI would be more strongly correlated with the RRS subscales than with the other measures, we compared these correlations with the correlation of the BSRI with each of the other measures. Given the multiple comparisons, false 
discovery rate was controlled with the adaptive Benjamini and Hochberg (2000) step-up procedure.

\section{Results}

\section{Factor structure and measurement invariance analyses}

Item descriptive statistics for the BSRI items are reported in Table 1. List-wise valid cases were 153 and 139 for samples 1 and 2 respectively, whereas no missing values were found in sample 3. Given that missing values could be considered at random (sample 1: Little's MCAR test: $\chi^{2}(24)=20.15, p=.688$; sample 2: Little's MCAR test: $\chi^{2}(24)=21.37, p=.617$, subsequent analyses were performed using a full information maximum likelihood (FIML) approach. FIML does not replace or impute missing values, but handles them within the analytic model (Table S1).

As could be expected given the content of the items, responses showed positive skewness (median: 1.14, 0.54, and 0.25 for samples 1, 2, and 3, respectively) and kurtosis values showed deviations, albeit not severe, from zero (median: 0.28, -1.03, and -1.12, for Sample 1, 2, and 3, respectively). Simulation studies (e.g., Hau \& Marsh, 2004) have shown that problems with maximum likelihood estimation arise with skewness at $>2$ and kurtosis $>5$. Therefore, we considered the data suitable for a MG-CFA analysis using Mplus 7.0's robust maximum likelihood estimator (MLR), that computes standard errors and tests of fit that are robust in relation to the relative non-normality of observations (Muthén \& Muthén, 1998-2012).

As shown in Table 2, the 13-item measurement model (Model 1) did not have an acceptable fit, i.e., did not show factor structure invariance over the samples. Thus, we inspected modification indices for the three samples and found that the highest values were those of the error covariance of item 8 and item 9 . In these cases, such parameter can be added to the model in order to improve model fit, but a (relatively) large unexplained covariance between two items can also suggest that they share some further source of covariance (other than the latent 
variable) or are redundant with each other. Hence, the removal of one of these items can lead to an improvement of the fit of the model without impairing its parsimony. We decided to remove item 8 from the model as additional modification indices suggested some unexplained covariance between it and other items. We then re-fitted the MG-CFA model and, although the fit substantially improved, it was still below acceptable values. On the basis of modification indices, we identified another item (item 3) that contributed to the misfit of the model. This item was removed from the scale and the fit of the measurement model was again tested. With the same iterative procedure three further items $(4,5$, and 13) were identified as problematic and removed from the scale one at a time. An optimal fit was thus achieved with an 8-item version of the BSRI (factor structure invariance; Model 6). Factor loadings are reported in Table 1.

With the factor structure invariance established, we could test the invariance of factor loadings. The weak invariance (Model 7) model showed an optimal fit and the difference between its fit indices and those of the factor structure invariance model suggested that the factor loadings could be considered equal across groups. Moreover, additional analyses demonstrated that the 8-item BRSI shows partial strong invariance (i.e., equivalent item intercepts) and partial strict invariance (i.e., equivalent item errors) (see Supplementary Material). Importantly, current guidelines suggests that, under the condition of partial measurement invariance, latent factors can be meaningfully compared and interpreted across different groups (Vandenberg \& Lance, 2000). Hence, these results support the validity and generalizability of the 8-item BSRI across multiple samples (see Appendix).

\section{Convergent and discriminant analyses}

The correlations of the BSRI scores with the scores on the other measures administered in sample 2 and 3 are reported in Table 3, along with descriptive statistics and Cronbach's alphas. We refer to the magnitude of the correlations, using Cohen's (1988) classification $(r<$ 
.10 negligible association; $.10 \leq r<.30$ : weak association; $.30 \leq r<.50$ moderate association; $r \geq .50$ strong association). The pattern of correlation of the 8-item BSRI with the other measures was very similar across the two samples. The pairwise tests for the difference between independent correlations were never statistically significant, namely, in no case the correlation between two measures in sample 2 was statistically different from the corresponding correlation in sample 3. This result suggests an adequate generalizability of the construct validity of the BSRI.

As can be seen in Table 3, the pattern of correlations was consistent with our predictions: Scores on the BSRI were moderately and positively correlated with both brooding and reflection. They were also positively associated with suppression and negatively associated with reappraisal, mindfulness, and positive affect. Finally, BSRI scores were positively linked to symptoms of depression and anxiety and negative mood.

To examine the construct validity of the BSRI, we conducted a test of the heterogeneity of dependent correlation coefficients (Meng et al., 1992). This test was significant in both samples (sample 2: $\chi^{2}(9)=31.94, p<.001, r=.48$; sample 3: $\chi^{2}(9)=68.57, p<.001, r=.59$ ), suggesting that at least two correlations of the BSRI with the other measures were statistically different from each other. Because we assumed that the BSRI would be more strongly correlated with the RRS subscales than with the other measures, we compared these correlations with the correlation of the BSRI with all the other measures (see Table S3). After adjustment for multiple comparisons, in both samples the correlation of BSRI with brooding was significantly higher than that of the BSRI with reappraisal, suppression, and positive affect. Possibly because of the higher statistical power afforded by the larger sample size, in sample 3 the correlation of BSRI scores with brooding was also stronger than the correlations with reflection and mindfulness. 
The same comparisons were conducted with reflection, and none were statistically significant in sample 2, while in sample 3 the correlation of BSRI with reflection was weaker than that with brooding, but stronger than those with reappraisal, suppression, and positive affect.

\section{Discussion Study 1}

In this study, we obtained a unidimensional 8-item measure, which showed adequate factor structure and measurement invariance. This held in both Dutch- and English-speaking individuals. We also examined the construct validity of the BSRI. The pattern of correlations was consistent with our predictions and the moderate rather than high correlations between the BSRI and the RRS subscales suggest that the BSRI captures state aspects rumination that are not subsumed under trait rumination. The correlation of BSRI with brooding was not higher than the correlation with depression, anxiety and negative mood in either sample. Although unexpected, this pattern of findings does not detract from the construct validity of the BSRI. Trait rumination is strongly associated with negative affect, depression, as well as anxiety (for a quantitative review see Mor \& Winquist, 2002), and consequently success in tests of discriminant validity is less likely. In keeping with this point, previous studies showed that state rumination is similarly correlated with trait rumination and depressive symptoms (Connolly \& Alloy, 2017; Marchetti et al., 2013).

Taken together, these findings indicate that the BSRI is a valid measure for state rumination, whose factor structure holds reliably across different samples. Furthermore, the BSRI places itself in the rumination's network by specifically capturing maladaptive component of repetitive negative thinking.

\section{Study 2}

In the second study, we tested the criterion validity of the BSRI and, to this end, we administered the BSRI before and after a rumination induction. To ascertain that the BSRI taps 
specifically into state rumination rather than self-focus in general, we compared scores on the BSRI when following a rumination induction (experimental condition) to a non-ruminative selffocus control condition. We expected an increase in BSRI scores following the rumination induction but not the non-ruminative self-focus induction. Moreover, because rumination contributes to negative mood (Nolen-Hoeksema et al., 2008), we reasoned that participants in the rumination condition would experience more negative mood compared to those in the control condition. Importantly, we expected that the effect of the rumination induction on negative mood would be mediated by the degree to which participants engage in state rumination, as indicated by their scores on the BSRI.

\section{Method}

Participants. We recruited 63 Dutch-speaking undergraduate students, of whom three were excluded from the study due to high levels of depressive symptoms (i.e., BDI-II > 28) or inadequate understanding of the procedure. The final sample consisted of 60 participants (females 67\%; mean age $22.08 \pm 3.98$, range: 18 -39). Participants received the equivalent of $€ 8$ for their participation.

\section{Measures.}

Brief State Rumination Inventory (BSRI). We used the 8-item version of the BSRI, as described above. The BSRI showed optimal levels of internal consistency before $(\alpha=.89)$ and after $(\alpha=.91)$ the experimental manipulation.

Beck Depression Inventory $-2^{\text {nd }}$ Edition (BDI-II; Beck, Steer, \& Brown, 1996). The BDI-II is a 21-item self-reported measure to assess depressive symptoms. Each item is a list of four statements arranged in increasing severity (from $0=$ 'absent' to $3=$ 'severe') about a specific symptom of depression. In this study, Cronbach's alpha was .87. 
Ruminative Responses Scale (RRS; Treynor et al., 2003). As in Study 2, we used the reflection and brooding subscales of the RRS. In the current sample, Cronbach's alpha of the two subscales was .81 and .82 , respectively.

Visual Analogue Scales for state mood. As in prior research (e.g., Rossi \& Pourtois, 2012), negative and positive mood were assessed using three 100-mm horizontal VAS each ("Right now I feel sad/depressed/down"; "Right now, I feel happy/excited/joyful"). The anchors were "completely disagree" and "completely agree". The positive and negative VAS measures showed excellent internal consistency before $(\alpha=.87$ and $\alpha=.88$, respectively) and after $(\alpha=$ .96 and $\alpha=.93$, respectively) the experimental manipulation.

Procedure. Participants completed the BDI-II and the RRS scales, and then watched a series of neutral video clips (5 minutes; Samson, Kreibig, Soderstrom, Wade, \& Gross, 2016) to neutralize mood before the completion of subsequent parts of the experiment. Next, they filled out the mood scales and the BSRI and were randomly assigned to either the experimental (rumination, $\mathrm{n}=30$ ) or the control (non-ruminative self-focus, $\mathrm{n}=30$ ) condition.

Participants in the rumination condition underwent the standard procedure developed by (Nolen-Hoeksema and Morrow (1993). They were asked to focus their attention on a series of 45 emotion-focused, symptom-focused, and self-focused phrases, each presented on the computer monitor for 15 secs, for a total of approximately 11 minutes. For example, participants were asked to think about "what your feelings might mean," and "why you react the way you do." Similarly, participants in the control condition were asked to focus on 45 self-related but non-ruminative or emotional phrases. For example, participants were asked to think about "what you had for breakfast", and "the books on your bookshelf."

Immediately following the experimental manipulation, participants completed the BSRI and the mood measures again. Then, they were asked to watch a series of positive video clips 
(5 minutes; Samson et al., 2015) to prevent possible negative effects of the experimental manipulation. Finally, they were debriefed about the study and paid.

\section{Results}

Mean scores on the BSRI were subjected to a mixed-design ANOVA with Condition (rumination vs. control) as a between-subject predictor and Time (pre- vs. post-induction) as a within-subject predictor ${ }^{3}$.

The analysis revealed a significant main effect of Time $\left(F(1,58)=4.15 p=.046, \eta_{G}^{2}=\right.$ $.02)^{4}$ and a marginally significant main effect of Condition $\left(F(1,58)=3.80, p=.056, \eta_{G}^{2}=.05\right)$, which was qualified by the predicted Time $\mathrm{x}$ Condition interaction $(F(1,58)=18.12, p<.001$, $\left.\eta_{G}^{2}=.06\right)$. Post-hoc analyses indicated that the groups did not differ before the rumination induction $(t(58)=0.10, p=.924$, Cohen's $d=0.08, M=209.03, S D=183.58$ and $M=205.07$, $S D=132.52$ for the control and the experimental conditions respectively). However, following the induction, BSRI scores were higher among participants in the rumination condition compared to those in the control condition $(t(58)=3.55, p=.001$, Cohen's $d=0.49, M=168.43$, $S D=164.96$ and $M=320.17, S D=166.57$ for the control and the experimental conditions respectively). Post-hoc tests also indicated that BSRI scores increased following the rumination induction $(t(58)=4.45, p<.001$, Cohen's $d=0.55)$, but remained constant following the nonruminative self-related thinking induction $(t(58)=1.56, p=.124$, Cohen's $d=0.33)$. When age, gender, BDI-II, brooding, and reflection scores were entered as covariates, the Time $\mathrm{x}$ Condition interaction remained significant $\left(F(1,53)=18.37, p<.001, \eta_{G}^{2}=.08\right)$.

We also tested whether our inductions led to significant change in negative and positive mood. A mixed-design ANOVA on the mean scores of the negative mood VAS scale, with Condition serving as a between-subject predictor and Time as a within-subject predictor, revealed a significant main effects of Time $\left(F(1,58)=9.44, p=.003, \eta_{G}^{2}=.04\right)$ but not of Condition $\left(F(1,58)=1.01, p=.319, \eta_{G}^{2}=.01\right)$, and a significant Time $\mathrm{x}$ Condition interaction 
$\left(F(1,58)=9.08, p=.004, \eta_{G}^{2}=.03\right)$. Post-hoc analyses indicated that the groups did not differ in negative mood before the rumination induction $(t(58)=0.63, p=.528$, Cohen's $d=0.21, M$ $=51.00, S D=52.40$ and $M=42.47, S D=51.79$ for the control and the experimental conditions respectively). However, following the induction, negative mood levels were higher among participants in the ruminative self-focus condition compared to those in the control condition $(t(58)=2.12, p=.039$, Cohen's $d=0.38, M=51.43, S D=51.07$ and $M=86.67, S D=75.60$ for the control and the experimental conditions respectively). Post-hoc tests also indicated that negative mood scores increased following the ruminative self-focus induction $(t(29)=4.30, p$ $<.001$, Cohen's $d=0.54$ ), but not following the non-ruminative self-related thinking induction $(t(29)=0.04, p=.966$, Cohen's $d=0.05)$. Results were unaffected by the specification of age, gender, BDI-II, brooding, and reflection scores as covariates.

The same analysis on positive mood scores revealed a significant main effect of Time $\left(F(1,58)=4.70, p=.034, \eta_{G}^{2}=.01 ;\right.$ Time $1: M=152.23, S D=61.14 ;$ Time $2: M=136.17, S D$ $=72.11)$ but the main effect of Condition and the Time $\mathrm{x}$ Condition interaction were nonsignificant $\left(F(1,58)=0.54, p=.467, \eta_{G}^{2}<.01\right.$, and $F(1,58)=0.34, p=.561, \eta_{G}^{2}<.01$, respectively). Results were unaffected by the specification of age, gender, BDI-II, Brooding, and Reflection scores as covariates.

Finally, we tested whether the change in negative mood was mediated by the change in state rumination ${ }^{5}$. Change scores were computed as the difference between the scores after the rumination induction and the baseline. We used the procedure described by Preacher and Hayes (2008) to compute a confidence interval around the indirect effect (i.e., the path through the mediator). In this procedure, statistical significance with alpha at .05 is indicated by a $95 \%$ bootstrap confidence interval (CI) that does not include zero. Results based on 5,000 biascorrected bootstrap re-samples of the data indicated that the change in state rumination mediated the effect of the rumination induction on change in negative mood (Indirect Effect $=$ 
$20.65, \mathrm{SE}=7.71 ; p<.001 ; 95 \%$ CI $[5.54,39.55]) ;$ see Figure S2). The total effect of the training condition on participants' change in mood was significant (Total Effect $=43.77, \mathrm{SE}=14.30, p$ $<.001 ; 95 \% \mathrm{CI}[14.30,15.73])$, but after accounting for the indirect effect, the remaining direct effect of induction on mood change was non-significant (Direct Effect $=23.12, \mathrm{SE}=15.87, p$ $=.145 ; 95 \%$ CI $[-7.99,54.40])$. Results were unaffected by entering age, gender, BDI-II, Brooding, and Reflection scores as covariates. In sum, our findings suggest that participants in the rumination condition engaged in more state rumination than did those in the control condition, which in turn increased their negative mood.

\section{Discussion Study 2}

This study examined the criterion validity of the BSRI by testing its sensitivity to capture manipulation-induced changes in ruminative thinking. BSRI scores changed only in response to the rumination induction but not the control condition. Moreover, in line with our expectations, changes in state rumination did lead to changes in negative mood (Mor \& Winquist. 2002). These effects were not due to pre-existing levels of depressive symptoms or trait rumination.

\section{General Discussion}

Ruminative thinking contributes to the development or maintenance of various forms of psychopathology (Nolen-Hoeksema \& Watkins, 2011; Smith \& Alloy, 2009). However, a psychometrically sound measure that allows to assess fluctuations in state rumination has been lacking. Existing measures have so far focused on specific and narrow forms of state rumination or do not provide enough psychometric information to be deemed reliable, robust, and valid (e.g., LeMoult et al., 2013; Roberts et al., 2013).

The aim of this series of studies was to develop and validate a new measure of state rumination, the Brief Rumination State Inventory (BSRI). In Study 1, we showed that the BSRI has excellent psychometric properties in terms of reliability, factor structure, and (partial) 
measurement invariance across three independent samples. Crucially, we demonstrated that the BSRI possesses an optimal stability of the factor structure and invariant factor loadings (i.e., weak invariance). Moreover, the BSRI items were usually characterized by invariant item intercepts and errors (i.e., partial strong and strict invariances; Byrne, Shavelson, \& Muthen, 1989). Taken together, these findings indicate that the BSRI is a psychometrically sound and robust instrument across multiple samples and languages (i.e., Dutch and English).

Furthermore, our study revealed that the BSRI has good convergent and discriminant validity as indicated by the pattern of links with other constructs in the nomological network of rumination. Our findings are in line with those obtained from experience sampling research, concerning the link between dispositional ruminative tendencies and momentary levels of rumination (Hilt et al., 2015; Koster et al., 2015). The findings we report in Study 1 add to this work, indicating that trait rumination and state rumination are interlinked, but are not the same. Second, the pattern of correlations obtained in Study 1 confirmed our hypotheses, in that the BSRI is positively associated with symptoms of emotional disorders and concurrent negative affect and negatively with helpful emotion regulation strategies and positive mood. Third, our study suggests that the BSRI is possibly more related to brooding than reflection (i.e., sample 3). This is particularly interesting considering that brooding is the more maladaptive form of rumination (Treynor et al., 2003), whereas reflection has occasionally be related to positive outcomes (Kwon \& Olson, 2007). Hence, the BSRI seems to map mainly onto the maladaptive aspects of ruminative thinking.

Finally, in Study 2, we demonstrated the sensitivity of the BSRI to an experimental manipulation of ruminative thinking. As compared to a non-ruminative self-focus induction, a rumination induction specifically increased scores on the BSRI. Moreover, the increase in state rumination could account for elevated negative mood following the induction. Taken together, 
these findings demonstrate the robustness, validity, and usefulness of the BSRI as a state measure of rumination.

The BSRI allows researchers to test causal links between rumination and factors that are thought to either lead to ruminative thinking or are considered outcomes of rumination. As the results of Study 2 indicate, the BSRI can assess reliably the effects of experimental manipulations of rumination. Moreover, recent theories of rumination suggest that cognitive factors, particularly biases and deficits in executive functions, have a causal role in rumination (e.g., Koster, De Lissnyder, Derakshan, \& De Raedt, 2011). However, empirical evidence for these models has often relied on correlational designs that assess the link between trait rumination and cognitive biases (e.g., Bernblum \& Mor, 2010; De Lissnyder, Derakshan, De Raedt, \& Koster, 2011). Only few studies have demonstrated the cognitive consequences of rumination (e.g., Philippot \& Brutoux, 2008; Watkins \& Brown, 2002). Recently, experimental work, utilizing cognitive training paradigms, has attempted to assess the causal role of cognitive deficits and biases in rumination (for a review, see Mor \& Daches, 2015). The BSRI can facilitate such research, by providing an assessment tool for immediate training effects, and causally linking cognitive biases and ruminative thinking.

Recent research has also attempted to elucidate contextual factors that affect rumination, such as stress or spontaneous thought (Marchetti, Koster, Klinger, \& Alloy, 2016; Zoccola, Dickerson, \& Lam, 2012). For example, an evaluative social environment was associated with increased rumination (Zoccola et al., 2012), whereas activation of a mental representation of an attachment figure after recalling upsetting memories reduced rumination (Selcuk, Zayas, Gunaydin, Hazan, \& Kress, 2012). In these studies, rumination was measured via thought records and ad-hoc measures. Using the BSRI could assist in understanding the conditions that foster or inhibit rumination. 
We acknowledge several limitations of this research. First, the relative lack of diversity in our samples may temper the generalizability of the findings. Therefore, future research should examine the BSRI in additional samples. For example, given the clinical relevance of the measure, testing the invariance of the factor structure of the BSRI in undergraduate VS. clinical samples could be informative. Second, while testing discriminant validity, we did not consider other types of repetitive negative thinking, such as worry and post-event processing (Watkins, 2008). Future studies should consider a broader range of unconstructive repetitive thoughts. Third, we did not assess incremental validity of the BSRI over other measures of state rumination. This decision was motivated by several considerations, the most important of which is that there is no "gold standard" measure for state rumination. The available measures either tap specific forms of ruminative thinking or are characterized by unknown and/or unreplicated psychometric properties and none of them have been used frequently enough for comparison across studies. Hence, testing the BSRI against unsatisfactory instruments would been poorly informative and potentially misleading. Future studies may consider evaluating the incremental utility of the BSRI against (semi-)structured interviews for rumination (Watkins \& Mason, 2002; Newby \& Moulds, 2012). Fourth, in Study 1 both different languages and administration methods were considered simultaneously. Although previous literature suggests that computerized and paper-and-pencil assessments seem to be equivalent (King, \& Miles, 1995), future studies should address this point explicitly.

In sum, the results of the studies described here, provide preliminary evidence for the validity and utility of the BSRI as a measure of state rumination. The BSRI may be useful in studies that assess causal links between rumination and associated factors and contextual factors that affect rumination, in experience sampling research that examines within person fluctuations in rumination, and in research on the interplay of stable trait tendencies and situational factors that affect negative thinking in psychopathology. Moreover, the BSRI has been developed and 
validated in both Dutch and English, in order to facilitate its dissemination within a variety of contexts, such research and clinical practice. 


\section{Compliance with Ethical Standards}

Conflict of Interest The authors declare that they have no conflict of interest.

Ethical Approval All procedures performed in studies involving human participants were in accordance with the ethical standards of the institutional and/or national research committee and with the 1964 Helsinki declaration and its later amendments or comparable ethical standards.

Animal Rights Statement No animal studies were carried out by the authors for this article.

Informed Consent Informed consent was obtained from all individual participants included in the study. 


\section{Footnotes}

${ }^{1}$ We acknowledge that the recently developed Exploratory Structural Equation Models (ESEM, Asparouhov \& Muthén, 2009) combine the advantages of both approaches, but in the case of a single factor an ESEM model corresponds to a CFA model.

${ }^{2}$ A simulated population according to the single factor model was generated, and the true model was tested with 10,000 replications of 141 cases each. Based on results from preliminary analyses, the assumed values for the population parameters were as follows: factor loadings $=$ .75 , error variances $=.4$, latent variance fixed at 1 . All the requested replications were completed.

${ }^{3}$ BSRI items 1 and 2 (partially) overlap with some rumination-inducing statements, as developed by Nolen-Hoeksema and Morrow (1993). After excluding items 1 and 2 from the BSRI total score, the reported findings did not change significantly.

${ }^{4}$ In line with recent guidelines (Olejnik \& Algina, 2003), we adopted the generalized eta squared $\left(\eta_{G}^{2}\right)$ as effect size statistic whenever ANOVAs are used.

${ }^{5}$ It is important to note that state rumination and state negative mood were measured concurrently. Hence, although theory-driven (Mor \& Winquist, 2002) and empirically plausible, the tested model (i.e., experimental manipulation $\rightarrow$ rumination changes $\rightarrow$ negative mood changes) is analytically equivalent to the alternative model (i.e., experimental manipulation $\rightarrow$ negative mood changes $\rightarrow$ rumination changes) (MacCallum, Wegener, Uchino, \& Fabrigar, 1993). 


\section{References}

Abend, R., Dan, O., Maoz, K., Raz, S., \& Bar-Haim, Y. (2014). Reliability, validity and sensitivity of a computerized visual analog scale measuring state anxiety. Journal of Behavior Therapy and Experimental Psychiatry, 45(4), 447-453. doi:10.1016/j.jbtep.2014.06.004

Augustine, A. A., \& Larsen, R. J. (2012). Is a Trait Really the Mean of States? Similarities and Differences Between Traditional and Aggregate Assessments of Personality. Journal of Individual Differences, 33(3), 131-137. doi:10.1027/1614-0001/a000083

Beck, A. T., Steer, R. A., \& Brown, G. K. (1996). Manual for the beck depression inventoryII. San Antonio: The Psychological Corporation.

Benjamini, Y., \& Hochberg, Y. (2000). On the adaptive control of the false discovery fate in multiple testing with independent statistics. Journal of Educational and Behavioral Statistics, 25(1), 60-83. doi:Doi 10.3102/10769986025001060

Bernblum, R., \& Mor, N. (2010). Rumination and Emotion-Related Biases in Refreshing Information. Emotion, 10(3), 423-432. doi:10.1037/a0018427

Borkenau, P., \& Ostendorf, F. (1998). The Big Five as states: How useful is the five-factor model to describe intraindividual variations over time?. Journal of Research in Personality, 32(2), 202-221. doi: 10.1006/jrpe.1997.2206

Brown, K. W., \& Ryan, R. M. (2003). The benefits of being present: Mindfulness and its role in psychological well-being. Journal of Personality and Social Psychology, 84(4), 822-848. doi:10.1037/0022-3514.84.4.822

Byrne, B. M., Shavelson, R. J., \& Muthen, B. (1989). Testing for the Equivalence of Factor Covariance and Mean Structures - the Issue of Partial Measurement Invariance. Psychological Bulletin, 105(3), 456-466. doi:10.1037//0033-2909.105.3.456

Chambers, R., Lo, B. C. Y., \& Allen, N. B. (2008). The impact of intensive mindfulness training on attentional control, cognitive style, and affect. Cognitive Therapy and Research, 32(3), 303-322. doi:10.1007/s10608-007-9119-0

Chen, F. F. (2007). Sensitivity of goodness of fit indexes to lack of measurement invariance. Structural Equation Modeling-a Multidisciplinary Journal, 14(3), 464-504. doi:10.1080/10705510701301834

Cheung, G. W., \& Rensvold, R. B. (2001). The effects of model parsimony and sampling error on the fit of structural equation models. Organizational Research Methods, 4(3), 236-264. doi:10.1177/109442810143004

Ciesla, J. A., Reilly, L. C., Dickson, K. S., Emanuel, A. S., \& Updegraff, J. A. (2012). Dispositional Mindfulness Moderates the Effects of Stress Among Adolescents: Rumination as a Mediator. Journal of Clinical Child and Adolescent Psychology, 41(6), 760-770. doi:10.1080/15374416.2012.698724

Cohen, J. (1988). Statistical power analysis for the behavioral sciences (2nd ed.). Hillsdale, NJ: Lawrence Earlbaum Associates.

Connolly, S. L., \& Alloy, L. B. (2017). Rumination interacts with life stress to predict depressive symptoms: An ecological momentary assessment study. Behaviour research and therapy, 97, 86-95. doi: 10.1016/j.brat.2017.07.006

D’Avanzato, C., Joormann, J., Siemer, M., \& Gotlib, I. H. (2013). Emotion regulation in depression and anxiety: examining diagnostic specificity and stability of strategy use. Cognitive Therapy and Research, 37(5), 968-980. doi: 10.1007/s10608-013-95370 
De Lissnyder, E., Derakshan, N., De Raedt, R., \& Koster, E. H. W. (2011). Depressive symptoms and cognitive control in a mixed antisaccade task: Specific effects of depressive rumination. Cognition \& Emotion, 25(5), 886-897. doi:10.1080/02699931.2010.514711

Du Troit, R., Pritchard, N., Heffernan, S., Simpson, T., \& Fonn, D. (2002). A Comparison of Three Different Scales for Rating Contact Lens Handling. OPTOMETRY AND VISION SCIENCE, 79(5), 313-320. doi:10.1097/00006324-200205000-00011

Ehring, T., Zetsche, U., Weidacker, K., Wahl, K., Schonfeld, S., \& Ehlers, A. (2011). The Perseverative Thinking Questionnaire (PTQ): Validation of a content-independent measure of repetitive negative thinking. Journal of Behavior Therapy and Experimental Psychiatry, 42(2), 225-232. doi:10.1016/j.jbtep.2010.12.003

Genet, J. J., \& Siemer, M. (2012). Rumination Moderates the Effects of Daily Events on Negative Mood: Results From a Diary Study. Emotion, 12(6), 1329-1339. doi:10.1037/a0028070

Gross, J. J. (1998). Antecedent- and response-focused emotion regulation: Divergent consequences for experience, expression, and physiology. Journal of Personality and Social Psychology, 74(1), 224-237. doi:10.1037/0022-3514.74.1.224

Gross, J. J., \& John, O. P. (2003). Individual differences in two emotion regulation processes: Implications for affect, relationships, and well-being. Journal of Personality and Social Psychology, 85(2), 348-362. doi:10.1037/0022-3514.85.2.348

Hau, K. T., \& Marsh, H. W. (2004). The use of item parcels in structural equation modelling: Non-normal data and small sample sizes. British Journal of Mathematical \& Statistical Psychology, 57, 327-351. doi:10.1111/j.2044-8317.2004.tb00142.x

Hau, K. T., Marsh, H. W., \& Wen, Z. (2004). Goodness of fit measures in structural equation modeling. International Journal of Psychology, 39(5-6), 513-513.

Henry, J. D., \& Crawford, J. R. (2005). The short-form version of the Depression Anxiety Stress Scales (DASS-21): Construct validity and normative data in a large non-clinical sample. British Journal of Clinical Psychology, 44, 227-239. doi:10.1348/014466505x29657

Hilt, L. M., Aldao, A., \& Fischer, K. (2015). Rumination and multi-modal emotional reactivity. Cognition \& Emotion, 29(8), 1486-1495. doi:10.1080/02699931.2014.989816

Horn, J. L. (1965). A Rationale and Test for the Number of Factors in Factor-Analysis. Psychometrika, 30(2), 179-185. doi:10.1007/Bf02289447

Jöreskog, K. G. (1971). Simultaneous factor analysis in several populations. Psychometrika, 36(4), 409-426. doi:10.1007/bf02291366

Katz, B. A., Lustig, N., Assis, Y., \& Yovel, I. (2017). Measuring Regulation in the Here and Now: The Development and Validation of the State Emotion Regulation Inventory (SERI). Psychological Assessment, 29(10), 1235-1248. doi:10.1037/pas0000420

King, W. C., \& Miles, E. W. (1995). A quasi-experimental assessment of the effect of computerizing noncognitive paper-and-pencil measurements: A test of measurement equivalence. Journal of Applied Psychology, 80(6), 643. doi : 10.1037/00219010.80.6.643

Kocovski, N. L., Endler, N. S., Rector, N. A., \& Flett, G. L. (2005). Ruminative coping and post-event processing in social anxiety. Behaviour Research and Therapy, 43(8), 971984. doi:10.1016/j.brat.2004.06.015

Koster, E. H. W., De Lissnyder, E., Derakshan, N., \& De Raedt, R. (2011). Understanding depressive rumination from a cognitive science perspective: The impaired 
disengagement hypothesis. Clinical Psychology Review, 31(1), 138-145. doi:10.1016/j.cpr.2010.08.005

Koster, E. H. W., Fang, L., Marchetti, I., Ebner-Priemer, U., Kirsch, P., Huffziger, S., \& Kuehner, C. (2015). Examining the Relation Between Mood and Rumination in Remitted Depressed Individuals: A Dynamic Systems Analysis. Clinical Psychological Science, 3(4), 619-627. doi:10.1177/2167702615578129

Kuehner, C., \& Weber, I. (1999). Responses to depression in unipolar depressed patients: an investigation of Nolen-Hoeksema's response styles theory. Psychological Medicine, 29(6), 1323-1333. doi: 10.1017/S0033291799001282

Kwon, P., \& Olson, M. L. (2007). Rumination and depressive symptoms: Moderating role of defense style immaturity. Personality and Individual Differences, 43(4), 715-724. doi:10.1016/j.paid.2007.01.012

LeMoult, J., Arditte, K. A., D'Avanzato, C., \& Joormann, J. (2013). State Rumination: Associations with Emotional Stress Reactivity and Attention Biases. Journal of Experimental Psychopathology, 4(5), 471-484. doi:10.5127/jep.029112

Lyubomirsky, S., Layous, K., Chancellor, J., \& Nelson, S. K. (2015). Thinking About Rumination: The Scholarly Contributions and Intellectual Legacy of Susan NolenHoeksema. Annual Review of Clinical Psychology, Vol 11, 11, 1-22. doi:10.1146/annurev-clinpsy-032814-112733

Lyubomirsky, S., \& Nolen-Hoeksema, S. (1995). Effects of Self-Focused Rumination on Negative Thinking and Interpersonal Problem-Solving. Journal of Personality and Social Psychology, 69(1), 176-190. doi: 10.1037//0022-3514.69.1.176

MacCallum, R. C., Wegener, D. T., Uchino, B. N., \& Fabrigar, L. R. (1993). The problem of equivalent models in applications of covariance structure analysis. Psychological bulletin, 114(1), 185-199. doi: 10.1037//0033-2909.114.1.185

Mahoney, A. E. J., McEvoy, P. M., \& Moulds, M. L. (2012). Psychometric properties of the Repetitive Thinking Questionnaire in a clinical sample. Journal of Anxiety Disorders, 26(2), 359-367. doi:10.1016/j.janxdis.2011.12.003

Marchetti, I., Koster, E. H. W., \& De Raedt, R. (2013). Rest-related dynamics of risk and protective factors for depression: A behavioral study. Clinical Psychological Science, 1(4), 443-451. doi:10.1177/2167702613489668

Marchetti, I., Koster, E. H. W., Klinger, E., \& Alloy, L. B. (2016a). Spontaneous Thought and Vulnerability to Mood Disorders: The Dark Side of the Wandering Mind. Clinical Psychological Science, 4(5), 835-857. doi:10.1371/journal.pone.0168612

Marsh, H. W., Hau, K. T., Balla, J. R., \& Grayson, D. (1998). Is more ever too much? The number of indicators per factor in confirmatory factor analysis. Multivariate Behavioral Research, 33(2), 181-220. doi:10.1207/s15327906mbr3302_1

Martin, L. L., \& Tesser, A. (1996). Some ruminative thoughts. In R. S. Wyer (Ed.), Advances in social cognition (Vol. 9, pp. 1-48). Hillsdale, NJ: Lawrence Erlbaum Associates.

McCabe, K. O., \& Fleeson, W. (2016). Are Traits Useful? Explaining Trait Manifestations as Tools in the Pursuit of Goals. Journal of Personality and Social Psychology, 110(2), 287-301. doi:10.1037/a0039490

McCullough, M. E., Bono, G., \& Root, L. M. (2007). Rumination, emotion, and forgiveness: Three longitudinal studies. Journal of Personality and Social Psychology, 92(3), 490505. doi:10.1037/0022-3514.92.3.490

Meng, X. L., Rosenthal, R., \& Rubin, D. B. (1992). Comparing Correlated CorrelationCoefficients. Psychological Bulletin, 111(1), 172-175. doi:10.1037//00332909.111.1.172 
Meredith, W. (1993). Measurement Invariance, Factor-Analysis and Factorial Invariance. Psychometrika, 58(4), 525-543. doi:10.1007/Bf02294825

Moberly, N. J., \& Watkins, E. R. (2008). Ruminative self-focus and negative affect: An experience sampling study. Journal of Abnormal Psychology, 117(2), 314-323. doi:10.1037/0021-843x.117.2.314

Molenaar, P. C. (2004). A manifesto on psychology as idiographic science: Bringing the person back into scientific psychology, this time forever. Measurement, 2(4), 201-218. doi: 10.1207/s15366359mea0204_1

Mor, N., \& Daches, S. (2015). Ruminative Thinking: Lessons Learned From Cognitive Training. Clinical Psychological Science, 3(4), 574-592. doi:10.1177/2167702615578130

Mor, N., Doane, L. D., Adam, E. K., Mineka, S., Zinbarg, R. E., Griffith, J. W., . . Nazarian, M. (2010). Within-person variations in self-focused attention and negative affect in depression and anxiety: A diary study. Cognition \& Emotion, 24(1), 48-62. doi:10.1080/02699930802499715

Mor, N., \& Winquist, J. (2002). Self-focused attention and negative affect: A meta-analysis. Psychological Bulletin, 128(4), 638-662. doi:10.1037//0033-2909.128.4.638

Muthen, L. K., \& Muthen, B. O. (2002). How to use a Monte Carlo study to decide on sample size and determine power. Structural Equation Modeling, 9(4), 599-620. doi:10.1207/S15328007sem0904_8

Muthén, L. K., \& Muthén, B. O. (1998-2012). Mplus user's guide (6th ed.). Los Angelese: Muthén \& Muthén.

Newby, J. M., \& Moulds, M. L. (2012). A comparison of the content, themes, and features of intrusive memories and rumination in major depressive disorder. British Journal of Clinical Psychology, 51(2), 197-205. doi: 10.1111/j.2044-8260.2011.02020.x

Nolen-Hoeksema, S. (1991). Responses to Depression and Their Effects on the Duration of Depressive Episodes. Journal of Abnormal Psychology, 100(4), 569-582. doi:10.1037/0021-843x.100.4.569

Nolen-Hoeksema, S. (2000). The role of rumination in depressive disorders and mixed anxiety/depressive symptoms. Journal of Abnormal Psychology, 109(3), 504-511. doi:10.1037/0021-843x.109.3.504

Nolen-Hoeksema, S., Stice, E., Wade, E., \& Bohon, C. (2007). Reciprocal relations between rumination and bulimic, substance abuse, and depressive symptoms in female adolescents. Journal of Abnormal Psychology, 116(1), 198-207. doi:10.1037/0021843x.116.1.198

Nolen-Hoeksema, S., \& Watkins, E. R. (2011). A Heuristic for Developing Transdiagnostic Models of Psychopathology: Explaining Multifinality and Divergent Trajectories. Perspectives on Psychological Science, 6(6), 589-609. doi:10.1177/1745691611419672

Nolen-Hoeksema, S., Wisco, B. E., \& Lyubomirsky, S. (2008). Rethinking Rumination. Perspectives on Psychological Science, 3(5), 400-424. doi:10.1111/j.17456924.2008.00088.x

Nolen-Hoeksema, S., \& Morrow, J. (1991). A Prospective-Study of Depression and Posttraumatic Stress Symptoms after a Natural Disaster - the 1989 Loma-Prieta Earthquake. Journal of Personality and Social Psychology, 61(1), 115-121. doi:10.1037//0022-3514.61.1.115 
Nolen-Hoeksema, S., \& Morrow, J. (1993). Effects of Rumination and Distraction on Naturally-Occurring Depressed Mood. Cognition \& Emotion, 7(6), 561-570. doi:10.1080/02699939308409206

Nolen-Hoeksema, S., Morrow, J., \& Fredrickson, B. L. (1993). Response Styles and the Duration of Episodes of Depressed Mood. Journal of Abnormal Psychology, 102(1), 20-28. doi:10.1037//0021-843x.102.1.20

Nolen-Hoeksema, S., Parker, L. E., \& Larson, J. (1994). Ruminative Coping with Depressed Mood Following Loss. Journal of Personality and Social Psychology, 67(1), 92-104. doi:10.1037//0022-3514.67.1.92

Olejnik, S., \& Algina, J. (2003). Generalized eta and omega squared statistics: measures of effect size for some common research designs. Psychological methods, 8(4), 434-447. doi: 10.1037/1082-989X.8.4.434

Peer, E., Brandimarte, L., Samat, S., \& Acquisti, A. (2017). Beyond the Turk: Alternative platforms for crowdsourcing behavioral research. Journal of Experimental Social Psychology, 70, 153-163. doi:10.1016/j.jesp.2017.01.006

Philippot, P., \& Brutoux, F. (2008). Induced rumination dampens executive processes in dysphoric young adults. Journal of Behavior Therapy and Experimental Psychiatry, 39(3), 219-227. doi:10.1016/j.jbtep.2007.07.001

Preacher, K. J., \& Hayes, A. F. (2008). Asymptotic and resampling strategies for assessing and comparing indirect effects in multiple mediator models. Behavior Research Methods, 40(3), 879-891. doi:10.3758/Brm.40.3.879

Roberts, H., Watkins, E. R., \& Wills, A. J. (2013). Cueing an unresolved personal goal causes persistent ruminative self-focus: An experimental evaluation of control theories of rumination. Journal of Behavior Therapy and Experimental Psychiatry, 44(4), 449455. doi:10.1016/j.jbtep.2013.05.004

Robinson, M. D., \& Clore, G. L. (2002). Episodic and semantic knowledge in emotional selfreport: Evidence for two judgment processes. Journal of Personality and Social Psychology, 83(1), 198-215. doi:10.1037//0022-3514.83.1.198

Rossi, V., \& Pourtois, G. (2012). Transient state-dependent fluctuations in anxiety measured using STAI, POMS, PANAS or VAS: a comparative review. Anxiety Stress and Coping, 25(6), 603-645. doi:10.1080/10615806.2011.582948

Ryan, J. M., Corry, J. R., Attewell, R., \& Smithson, M. J. (2002). A comparison of an electronic version of the SF-36 General Health Questionnaire to the standard paper version. Quality of Life Research, 11(1), 19-26. doi:10.1023/A:1014415709997

Samson, A. C., Kreibig, S. D., Soderstrom, B., Wade, A. A., \& Gross, J. J. (2016). Eliciting positive, negative and mixed emotional states: A film library for affective scientists. Cognition \& Emotion, 30(5), 827-856. doi:10.1080/02699931.2015.1031089

Selcuk, E., Zayas, V., Gunaydin, G., Hazan, C., \& Kress, E. (2012). Mental Representations of Attachment Figures Facilitate Recovery Following Upsetting Autobiographical Memory Recall. Journal of Personality and Social Psychology, 103(2), 362-378. doi:10.1037/a0028125

Smith, J. M., \& Alloy, L. B. (2009). A roadmap to rumination: A review of the definition, assessment, and conceptualization of this multifaceted construct. Clinical Psychology Review, 29(2), 116-128. doi:10.1016/j.cpr.2008.10.003

Steinmetz, H. (2013). Analyzing observed composite differences across groups: Is partial measurement invariance enough? Methodology, 9(1), 1-12. doi:10.1027/16142241/a000049 
Stone, A. A., Shiffman, S., Schwartz, J. E., Broderick, J. E., \& Hufford, M. R. (2002). Patient non-compliance with paper diaries. British Medical Journal, 324(7347), 1193-1194. doi:10.1136/bmj.324.7347.1193

Takano, K., \& Tanno, Y. (2011). Diurnal Variation in Rumination. Emotion, 11(5), 10461058. doi:10.1037/a0022757

Tavakol, M., \& Dennick, R. (2011). Making sense of Cronbach's alpha. International Journal of Medical Education, 2, 53-55. doi:10.5116/ijme.4dfb.8dfd

Trapnell, P. D., \& Campbell, J. D. (1999). Private self-consciousness and the five-factor model of personality: Distinguishing rumination from reflection. Journal of Personality and Social Psychology, 76(2), 284-304. doi:10.1037/0022-3514.76.2.284

Treynor, W., Gonzalez, R., \& Nolen-Hoeksema, S. (2003). Rumination reconsidered: A psychometric analysis. Cognitive Therapy and Research, 27(3), 247-259. doi:10.1023/A:1023910315561

Vandenberg, R. J., \& Lance, C. E. (2000). A review and synthesis of the measurement invariance literature: Suggestions, practices, and recommendations for organizational research. Organizational research methods, 3(1), 4-70. doi: 10.1177/109442810031002

Watkins, E. R. (2008). Constructive and unconstructive repetitive thought. Psychological Bulletin, 134(2), 163-206. doi:10.1037/0033-2909.134.2.163

Watkins, E., \& Brown, R. G. (2002). Rumination and executive function in depression: an experimental study. Journal of Neurology Neurosurgery and Psychiatry, 72(3), 400402. doi:10.1136/jnnp.72.3.400

Watkins, E. R., \& Nolen-Hoeksema, S. (2014). A Habit-Goal Framework of Depressive Rumination. Journal of Abnormal Psychology, 123(1), 24-34. doi:10.1037/a0035540

Watkins, E., \& Mason, A. (2002). Mood as input and rumination. Personality and Individual Differences, 32(4), 577-587. doi: 10.1016/s0191-8869(01)00058-7

Watson, D., Clark, L. A., \& Tellegen, A. (1988). Development and Validation of Brief Measures of Positive and Negative Affect - the Panas Scales. Journal of Personality and Social Psychology, 54(6), 1063-1070. doi:10.1037/0022-3514.54.6.1063

Zoccola, P. M., Dickerson, S. S., \& Lam, S. (2012). Eliciting and Maintaining Ruminative Thought: The Role of Social-Evaluative Threat. Emotion, 12(4), 673-677. doi:10.1037/a0027349 


\section{Appendix}

\section{Brief State Rumination Inventory (BSRI)}

Instructions: Please respond to the following items by referring to the way you feel or think right now. For each item, please mark a vertical line on the horizontal line to indicate the degree to which you agree or disagree with the statement.

1. Right now, I am reflecting about my mood.

2. Right now, I wonder why I react the way I do.

3. Right now, I wonder why I always feel the way I do.

4. Right now, I am thinking: "why do I have problems other people don't have?".

5. Right now, I am rehashing in my mind recent things I've said or done.

6. Right now, I am thinking: "why can't I handle things better?".

7. Right now, it is hard for me to shut off negative thoughts about myself.

8. Right now, I wonder why I can't respond in a better way.

Note: All items are measured on a 100-mm visual analogue scale (VAS) ranging from “completely disagree" (0) to "completely agree" (100).

Scoring instructions: All items are forward scored. The BSRI total score is computed by summing all items. 
Tables

Table 1

Item descriptive statistics and factor loadings in sample 1 ( $n=155$; left subcolumn), sample 2 ( $n=141$; central subcolumn), and sample 3 ( $n=$ 199; left subcolumn)

\begin{tabular}{|c|c|c|c|}
\hline Item & $\mathrm{M}$ & $\mathrm{SD}$ & Factor Loadings \\
\hline 1. Right now, I am reflecting about my mood. & 40.4855 .6956 .38 & 26.2528 .8428 .79 & $.60 \quad .54 \quad .54$ \\
\hline 2. Right now, I wonder why I react the way I do. & 26.6232 .8739 .06 & 24.8426 .9529 .45 & .74 .77 .76 \\
\hline $\begin{array}{l}\text { 3. Right now, I am thinking about the possible meaning of the way I } \\
\text { feel. }\end{array}$ & I 40.4646 .1243 .85 & 26.7328 .7728 .72 & \\
\hline $\begin{array}{l}\text { 4. Right now, I dwell on negative aspects of myself that I wish I'd } \\
\text { stop thinking about. }\end{array}$ & 26.7533 .3440 .10 & 27.3028 .1232 .63 & \\
\hline $\begin{array}{l}\text { 5. Right now, I am wondering why things happen to me the way } \\
\text { they do. }\end{array}$ & 26.2829 .8939 .67 & 26.1626 .0530 .65 & \\
\hline 6. Right now, I wonder why I always feel the way I do. & $23.1433 .22 \quad 37.61$ & 23.8827 .0629 .53 & $.82 \quad 86 \quad 79$ \\
\hline $\begin{array}{l}\text { 7. Right now, I am thinking: "why do I have problems other people } \\
\text { don't have?". }\end{array}$ & 21.3825 .7534 .33 & $24.42 \quad 23.2031 .51$ & $.77 \quad 61 \quad 69$ \\
\hline $\begin{array}{l}\text { 8. Right now, I am thinking of a situation that happened to me, } \\
\text { wishing it had gone better. }\end{array}$ & 29.8839 .4343 .04 & 29.6031 .8933 .06 & \\
\hline $\begin{array}{l}\text { 9. Right now, I am rehashing in my mind recent things I've said or } \\
\text { done. }\end{array}$ & 35.1037 .8439 .09 & 29.0531 .6330 .05 & $.51 .65 \quad .66$ \\
\hline 10. Right now, I am thinking: “why can't I handle things better?”. & 24.6131 .2635 .38 & 25.5528 .3430 .83 & $.78 \quad .76 \quad .89$ \\
\hline $\begin{array}{l}\text { 11. Right now, it is hard for me to shut off negative thoughts about } \\
\text { myself. }\end{array}$ & 20.5424 .8536 .26 & 24.7226 .5932 .68 & $.80 \quad .84 \quad .74$ \\
\hline 12. Right now, I wonder why I can't respond in a better way. & 22.8326 .7435 .15 & 24.5725 .8230 .64 & $.80 \quad .72 \quad .88$ \\
\hline 13. Right now, I am trying to understand why I feel the way I do. & $25.6035 .05 \quad 42.81$ & 24.9128 .7031 .02 & \\
\hline
\end{tabular}

Note: M: mean score; SD: standard deviation 
Table 2

Multi-Group Confirmatory Factor Analysis Models for the BSRI

\begin{tabular}{|c|c|c|c|c|c|c|}
\hline Model & $\chi^{2}$ & $\mathrm{df}$ & SCF & $\mathrm{CFI}$ & TLI & RMSEA \\
\hline \multicolumn{7}{|l|}{ Factor structure invariance } \\
\hline Model 1. 13-item BSRI & 656.73 & 195 & 1.420 & .849 & .819 & .120 \\
\hline Model 2. 12-item BSRI (without item 8) & 514.77 & 162 & 1.399 & .872 & .844 & .115 \\
\hline Model 3. 11-item BSRI (without items 8, 3) & 403.20 & 154 & 1.366 & .894 & .886 & .099 \\
\hline Model 4. 10-item BSRI (without items 8, 3, 4) & 282.72 & 105 & 1.419 & .913 & .888 & .101 \\
\hline Model 5. 9-item BSRI (without items $8,3,4,5$ ) & 178.84 & 81 & 1.422 & .943 & .924 & .086 \\
\hline Model 6. 8-item BSRI (without items 8, 3, 4, 5, 13) & 106.25 & 60 & 1.389 & .963 & .954 & .068 \\
\hline \multicolumn{7}{|l|}{ Weak invariance } \\
\hline Model 7. Model $6+$ Weak invariance model & 138.56 & 76 & 1.314 & .956 & .951 & .071 \\
\hline
\end{tabular}

Note: $\chi^{2}$ : chi-square statistic; df: degrees of freedom of the chi-square statistic; SCF: scaling correction factor; CFI: Comparative Fit Index;

TLI: Tucker-Lewis Index; RMSEA: Root Mean Square Error of Approximation. 
Table 3

Correlations of BSRI scores with measures of rumination, emotional regulation, anxiety, depression, stress, affect, and mindfulness in sample 2 $(n=141$, lower triangle $)$ and sample $3(n=199$, upper triangle). Scale internal consistency measures and descriptive statistics are also reported.

\begin{tabular}{|c|c|c|c|c|c|c|c|c|c|c|c|c|c|c|}
\hline Scale & 1 & 2 & 3 & 4 & 5 & 6 & 7 & 8 & 9 & 10 & 11 & Sample $3 \alpha$ & Sample 3 & MSample 3 SD \\
\hline 1. BSRI & & $.60 * *$ & $.41 * *$ & $-.17 *$ & .12 & $.49 * *$ & $.49 * *$ & $.54 * *$ & $.54 * *$ & $-.18^{*}$ & $-.39 * *$ & .91 & 313.26 & 190.33 \\
\hline 2. RRS - Brooding & $.49 * *$ & & $.58 * *$ & $-.24 * *$ & .01 & $.54 * *$ & $.59 * *$ & $.60 * *$ & $.45^{* *}$ & $-.25 * *$ & $-.42 * *$ & .85 & 10.43 & 3.67 \\
\hline 3. RRS - Reflection & $.37 * *$ & $.45 * *$ & & -.03 & -.07 & $.47 * *$ & $.36^{* *}$ & $.48^{* *}$ & $.31 * *$ & -.11 & $-.22 * *$ & .81 & 9.80 & 3.34 \\
\hline 4. ERQ - Emotion Reappraisal & -.15 & -.16 & -.06 & & -.09 & $-.18 *$ & $-.46 * *$ & $-.25 * *$ & $-.25 * *$ & $.47 * *$ & .11 & .92 & 28.46 & 7.46 \\
\hline 5. ERQ - Emotion Suppression & $.21 *$ & $.20 *$ & $.21^{*}$ & -.16 & & $.16^{*}$ & $.22 * *$ & .11 & $.14 *$ & -.13 & $-.22 * *$ & .81 & 16.27 & 5.45 \\
\hline 6. DASS - Anxiety & $.41^{* *}$ & $.27 * *$ & .12 & -.12 & .08 & & $.60 * *$ & $.72 * *$ & $.54 * *$ & $-.14^{*}$ & $-.37 * *$ & .85 & 10.89 & 3.85 \\
\hline 7. DASS - Depression & $.54 * *$ & $.44 * *$ & $.40 * *$ & $-.35 * *$ & $.39 * *$ & $.42 * *$ & & $.69 * *$ & $.50 * *$ & $-.40 * *$ & $-.37 * *$ & .92 & 12.87 & 5.56 \\
\hline 8. DASS - Stress & $.44^{* *}$ & $.38 * *$ & $.35^{* *}$ & $-.20 *$ & .09 & $.39 * *$ & $.48 * *$ & & $.58 * *$ & $-.24 * *$ & $-.47 * *$ & .87 & 13.20 & 4.54 \\
\hline 9. PANAS - Negative Affect & $.52 * *$ & $.43 * *$ & $.33^{* *}$ & $-.22 * *$ & $.28 * *$ & $.47 * *$ & $.53 * *$ & $.60 * *$ & & $-.20 * *$ & $-.29 * *$ & .93 & 15.22 & 7.12 \\
\hline 10. PANAS - Positive Affect & $-.23 * *$ & $-.28 * *$ & $-.18 *$ & $.35^{* *}$ & $-.46 * *$ & $-.22 * *$ & $-.39 * *$ & -.16 & $-.30 * *$ & & $.33 * *$ & .93 & 25.24 & 9.30 \\
\hline 11. MAAS & $-.31 * *$ & $-.33 * *$ & $-.20 *$ & .12 & $-.23 * *$ & $-.26 * *$ & $-.40 * *$ & $-.38 * *$ & $-.40 * *$ & $.30 * *$ & & .92 & 60.94 & 14.70 \\
\hline Sample $2 \alpha$ & .89 & .72 & .69 & .78 & .81 & .79 & .88 & .88 & .82 & .84 & .83 & & & \\
\hline Sample 2 M & 268.16 & 11.09 & 11.29 & 27.41 & 11.56 & 9.75 & 11.17 & 13.84 & 22.48 & 33.31 & 63.36 & & & \\
\hline Sample 2 SD & 165.20 & 2.98 & 2.91 & 5.44 & 4.70 & 3.17 & 4.44 & 5.02 & 6.64 & 5.42 & 9.62 & & & \\
\hline
\end{tabular}

Note: $*: p<.05 ; * *: p<.01 ; * * *: p<.001 . R R S:$ Ruminative Response Scale; ERQ: Emotional Regulation Questionnaire; DASS: Depression-Anxiety-Stress Scales; PANAS:

Positive and Negative Affect Schedule; MAAS: Mindful Attention Awareness Scale; $M=$ mean; SD = standard deviation 
Table S1

\section{Supplementary Materials}

Full Information Maximum Likelihood Variance/Covariance Matrix and Means for the Brief State Rumination Inventory (BSRI) items in Study 1

\begin{tabular}{|c|c|c|c|c|c|c|c|c|c|c|c|c|c|}
\hline & BRSI01 & BRSI02 & BRSI03 & BRSI04 & BRSI05 & BRSI06 & BRSI07 & BRSI08 & BRSI09 & BRSI10 & BRSI11 & BRSI12 & BRSI13 \\
\hline \multicolumn{14}{|c|}{ sample $1(n=155)$} \\
\hline BRSI01 & 684.73 & & & & & & & & & & & & \\
\hline BRSI02 & 381.45 & 612.01 & & & & & & & & & & & \\
\hline BRSI03 & 509.30 & 405.29 & 709.86 & & & & & & & & & & \\
\hline BRSI04 & 399.12 & 417.06 & 442.28 & 740.34 & & & & & & & & & \\
\hline BRSI05 & 354.50 & 293.77 & 414.65 & 444.23 & 679.72 & & & & & & & & \\
\hline BRSI06 & 322.86 & 402.99 & 395.69 & 451.71 & 413.37 & 566.34 & & & & & & & \\
\hline BRSI07 & 289.05 & 299.84 & 330.32 & 421.57 & 419.15 & 346.55 & 592.69 & & & & & & \\
\hline BRSI08 & 241.51 & 204.64 & 295.65 & 375.56 & 480.14 & 343.59 & 501.13 & 867.10 & & & & & \\
\hline BRSI09 & 212.44 & 221.19 & 292.05 & 312.54 & 320.00 & 270.83 & 282.49 & 417.87 & 838.66 & & & & \\
\hline BRSI10 & 265.78 & 336.23 & 295.24 & 352.91 & 299.15 & 368.80 & 408.30 & 334.20 & 296.39 & 648.55 & & & \\
\hline BRSI11 & 292.66 & 312.27 & 321.65 & 467.42 & 359.13 & 385.38 & 401.28 & 411.36 & 279.70 & 422.60 & 607.04 & & \\
\hline BRSI12 & 279.44 & 384.59 & 329.00 & 377.41 & 338.18 & 382.99 & 352.00 & 359.01 & 352.36 & 391.74 & 370.28 & 599.82 & \\
\hline BRSI13 & 372.36 & 277.39 & 446.88 & 427.79 & 436.94 & 393.59 & 334.91 & 390.65 & 309.49 & 333.94 & 375.15 & 351.38 & 616.28 \\
\hline Means & 40.48 & 26.52 & 40.47 & 26.75 & 26.28 & 23.14 & 21.38 & 29.87 & 35.10 & 24.61 & 20.54 & 22.83 & 25.60 \\
\hline
\end{tabular}

sample $2(n=141)$

BRSI01

BRSI02

BRSI03

BRSI04

BRSI05

BRSI06
826.10

$393.92 \quad 721.13$

$550.21 \quad 438.32 \quad 821.75$

$\begin{array}{llll}351.58 & 506.67 & 511.38 & 781.56\end{array}$

$\begin{array}{lllll}285.12 & 454.85 & 369.33 & 430.71 & 673.69\end{array}$

$\begin{array}{llllll}398.44 & 510.69 & 466.67 & 530.84 & 451.67 & 727.24\end{array}$ 


\begin{tabular}{|c|c|c|c|c|c|c|c|c|c|c|c|c|c|}
\hline BRSI07 & 132.33 & 291.39 & 205.84 & 308.22 & 383.59 & 332.59 & 534.51 & & & & & & \\
\hline BRSI08 & 288.26 & 432.76 & 530.97 & 478.14 & 472.21 & 462.78 & 322.65 & 1009.74 & & & & & \\
\hline BRSI09 & 324.30 & 375.93 & 545.68 & 404.15 & 410.90 & 455.09 & 270.95 & 735.62 & 993.10 & & & & \\
\hline BRSI10 & 241.11 & 397.61 & 356.78 & 426.93 & 409.91 & 472.49 & 308.91 & 499.70 & 499.72 & 794.54 & & & \\
\hline BRSI11 & 341.98 & 457.09 & 403.34 & 460.85 & 411.54 & 506.61 & 320.68 & 416.47 & 449.48 & 510.09 & 702.24 & & \\
\hline BRSI12 & 278.28 & 368.06 & 305.95 & 269.39 & 308.60 & 413.07 & 283.16 & 389.81 & 413.42 & 441.83 & 381.64 & 662.01 & \\
\hline BRSI13 & 422.37 & 375.01 & 566.94 & 432.21 & 412.18 & 477.62 & 258.84 & 481.16 & 613.78 & 437.73 & 477.77 & 371.38 & 817.78 \\
\hline Means & 55.69 & 32.87 & 46.12 & 33.39 & 29.89 & 33.22 & 25.75 & 39.43 & 37.84 & 31.19 & 24.85 & 26.75 & 35.05 \\
\hline
\end{tabular}

sample $3(n=199)$

BRSI01

BRSI02

BRSI03

BRSI04

BRSI05

BRSI06

BRSI07

BRSI08

BRSI09

BRSI10

BRSI11

BRSI12

BRSI13

Means

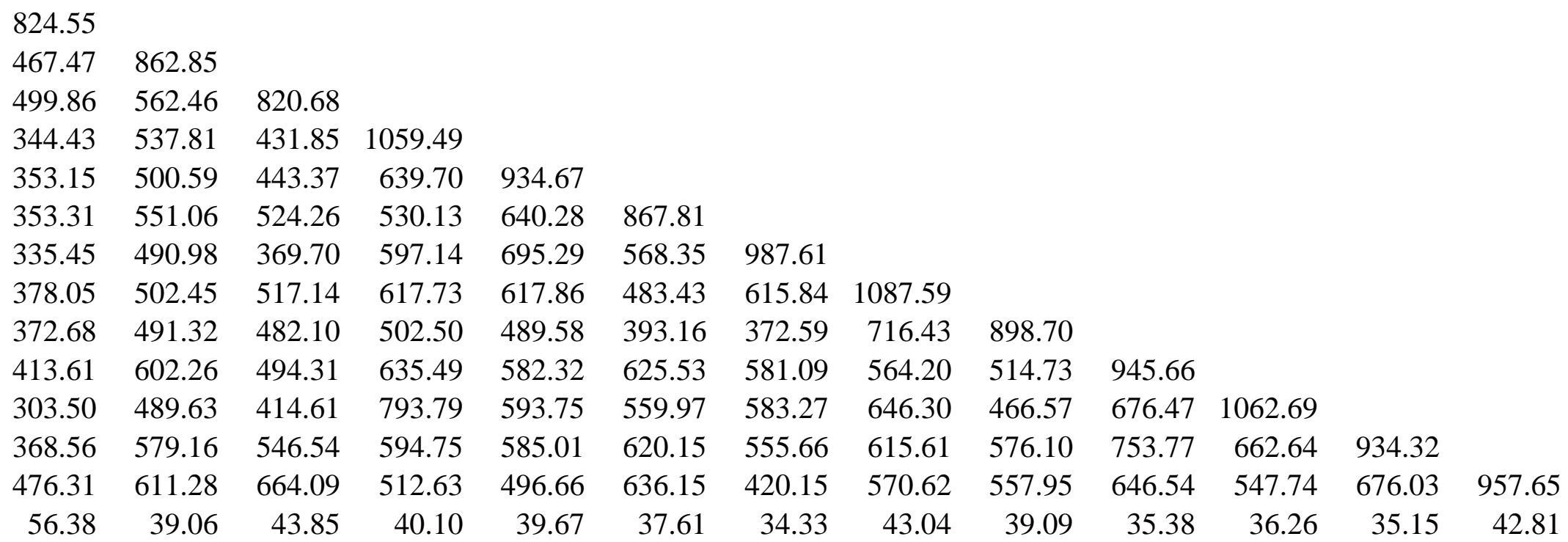




\section{Test of strong and strict invariance}

\section{Data Analysis Strategy}

In the context of MG-CFA across samples 1, 2, and 3, we tested two measurement invariance models in which indicator means (i.e., the intercepts of responses to individual items; strong invariance) and item error variances (strict invariance) were invariant across groups. If factor loadings and item intercepts are invariant across groups, then changes in the latent factor means can reasonably be interpreted as differences in the latent constructs. If item error variances are also invariant across groups, observed scale scores can be reliably compared. We also allowed for partial invariance, indicating that invariance is warranted and valid inferences between latent factor means in the model can be made, if at least two loadings and intercepts are equal across groups (Byrne, Shavelson, \& Muthen, 1989). Full invariance of error variances is desirable to be able to compare the manifest means (Steinmetz, 2013).

\section{Results}

We tested (partial) strong and (partial) strict invariance (Table S2). When we imposed equality of item intercepts (Model 8), the model fit substantially dropped. The inspection of modification indices suggested to remove the invariance constraint for the intercept of item 1 (Model 9). This model had an optimal fit, suggesting a partial strong invariance, i.e., latent scores could be reliably compared. Finally, we tested a model in which error variances were constrained to equality (Model 10). Again, we observed a substantial drop in model fit that could be addressed by releasing the constraints on error variances of items 11 and 7 .

Although desirable, full invariance model is often practically impossible and scientifically unrealistic (Steenkamp \& Baumgartner, 1998). In keeping with this, Byrne and colleagues (1989) recommend that, even under the condition of partial invariance, latent factors can be meaningfully compared and interpreted across different groups. In conclusion, the 
analyses confirmed that the BSRI is a psychometrically sound instrument to measure inter- and intra-individual differences in state rumination.

Table S2

Multi-Group Confirmatory Factor Analysis Models for the BSRI

\begin{tabular}{lrrrrrr} 
Model & $\chi^{2}$ & df & SCF & CFI & TLI RMSEA \\
\hline $\begin{array}{l}\text { Invariance (constrained) models } \\
\text { Model 7. 8-item BSRI + Weak invariance model }\end{array}$ & & & & & & \\
& & & & & & \\
Model 8. Model 7 + Strong invariance model & 178.56 & 76 & 1.314 & .956 & .951 & .071 \\
$\begin{array}{l}\text { Model 9. Partial strong invariance (Model 8 + free } \\
\text { intercept of item 1) }\end{array}$ & 162.96 & 80 & 1.267 & .938 & .943 & .077 \\
$\begin{array}{l}\text { Model 10. Model 9 + Strict invariance } \\
\text { Model 11. Partial strict invariance (Model 10+ free } \\
\text { error variance of item 11) }\end{array}$ & 214.92 & 104 & 1.310 & .922 & .937 & .080 \\
$\begin{array}{l}\text { Model 12. Partial strict invariance (Model 11+ free } \\
\text { error variance of item 7) }\end{array}$ & 193.57 & 102 & 1.303 & .935 & .947 & .074 \\
\hline
\end{tabular}

Note: $\chi^{2}:$ chi-square statistic; df: degrees of freedom of the chi-square statistic; SCF: scaling correction factor; CFI: Comparative Fit Index; TLI: Tucker-Lewis Index; RMSEA: Root Mean Square Error of Approximation.

Byrne, B. M., Shavelson, R. J., \& Muthen, B. (1989). Testing for the Equivalence of Factor Covariance and Mean Structures - the Issue of Partial Measurement Invariance. Psychological Bulletin, 105(3), 456-466. doi:10.1037//0033-2909.105.3.456

Steinmetz, H. (2013). Analyzing observed composite differences across groups: Is partial measurement invariance enough? Methodology, 9(1), 1-12. doi:10.1027/16142241/a000049

Steenkamp, J. B. E., \& Baumgartner, H. (1998). Assessing measurement invariance in crossnational consumer research. Journal of consumer research,25(1), 78-90. doi: $10.1086 / 209528$ 
Table S3

Post-hoc comparisons for the Meng el al. (1992)'s test of dependent correlation coefficients for BSRI.

\begin{tabular}{|c|c|c|c|c|}
\hline \multirow[b]{2}{*}{$r$ with RSS-Brooding vs $r$ with } & \multicolumn{2}{|c|}{ sample 2} & \multicolumn{2}{|c|}{ sample 3} \\
\hline & raw p & adj. p & raw $\mathrm{p}$ & adj. p \\
\hline RRS - Reflection & .217 & .390 & .014 & .025 \\
\hline ERQ - Emotion Reappraisal & .001 & .011 & $<.001$ & $<.001$ \\
\hline ERQ - Emotion Suppression & .007 & .031 & $<.001$ & $<.001$ \\
\hline DASS - Anxiety & .401 & .601 & .134 & .172 \\
\hline DASS - Depression & .569 & .667 & .134 & .172 \\
\hline DASS - Stress & .593 & .667 & .396 & .396 \\
\hline PANAS - Negative Affect & .736 & .736 & .396 & .396 \\
\hline PANAS - Positive Affect & .012 & .035 & $<.001$ & $<.001$ \\
\hline \multirow[t]{2}{*}{ MAAS } & .071 & .160 & .007 & .016 \\
\hline & \multicolumn{2}{|c|}{ sample 2} & \multicolumn{2}{|c|}{ sample 3} \\
\hline$r$ with RSS-Reflection vs $r$ with & raw $p$ & adj.p & raw $p$ & adj.p \\
\hline RRS - Brooding & .217 & .325 & .014 & .035 \\
\hline ERQ - Emotion Reappraisal & .047 & .320 & .012 & .035 \\
\hline ERQ - Emotion Suppression & .143 & .321 & .003 & .024 \\
\hline DASS - Anxiety & .693 & .693 & .338 & .380 \\
\hline DASS - Depression & .071 & .320 & .338 & .380 \\
\hline DASS - Stress & .483 & .621 & .108 & .162 \\
\hline PANAS - Negative Affect & .116 & .321 & .108 & .162 \\
\hline PANAS - Positive Affect & .197 & .325 & .016 & .035 \\
\hline MAAS & .570 & .641 & .820 & .820 \\
\hline
\end{tabular}


Figure S1

Scree-plot and parallel analyses results across the three samples.

Sample 1

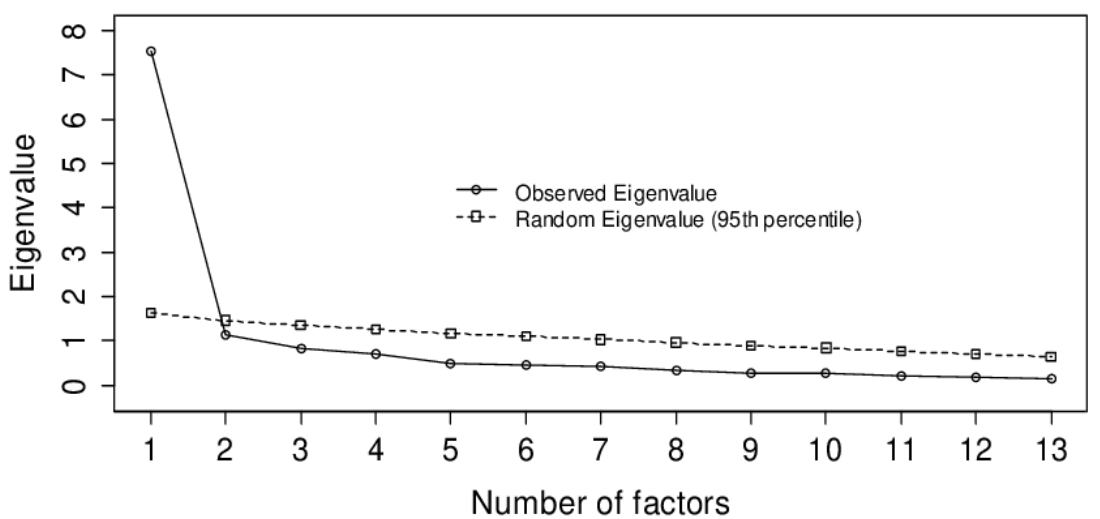

Sample 3

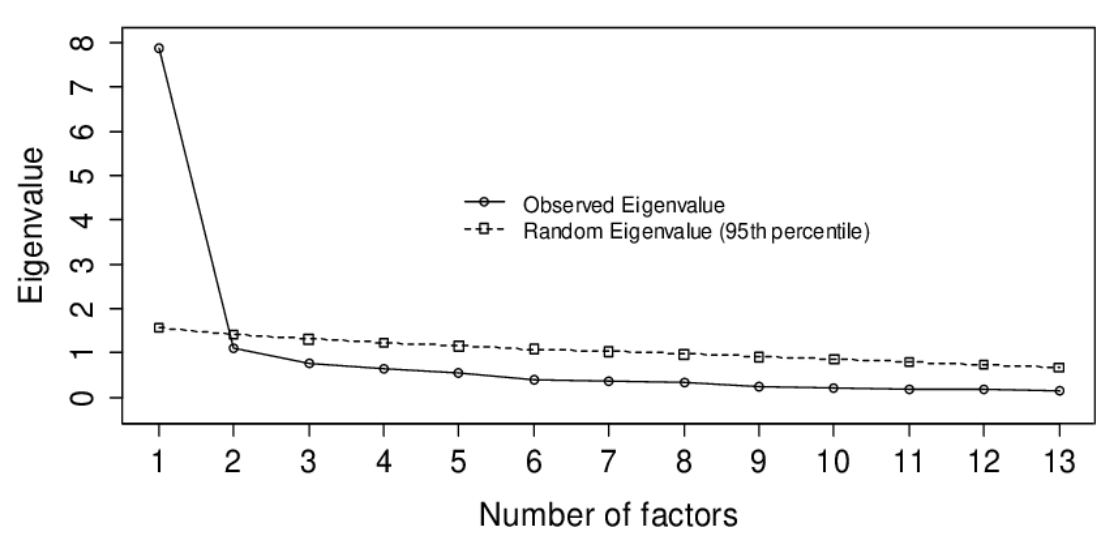

Sample 2

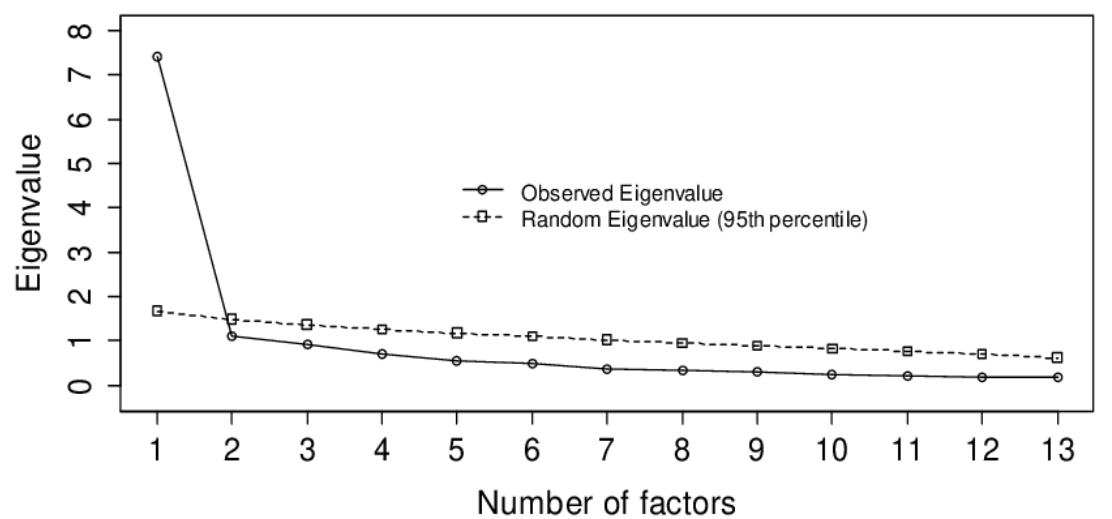


Figure S2

Mediation analysis showing that the effect of rumination induction (VS. non-ruminative self-focus induction) on negative mood is mediated by change in state rumination (BRSI).

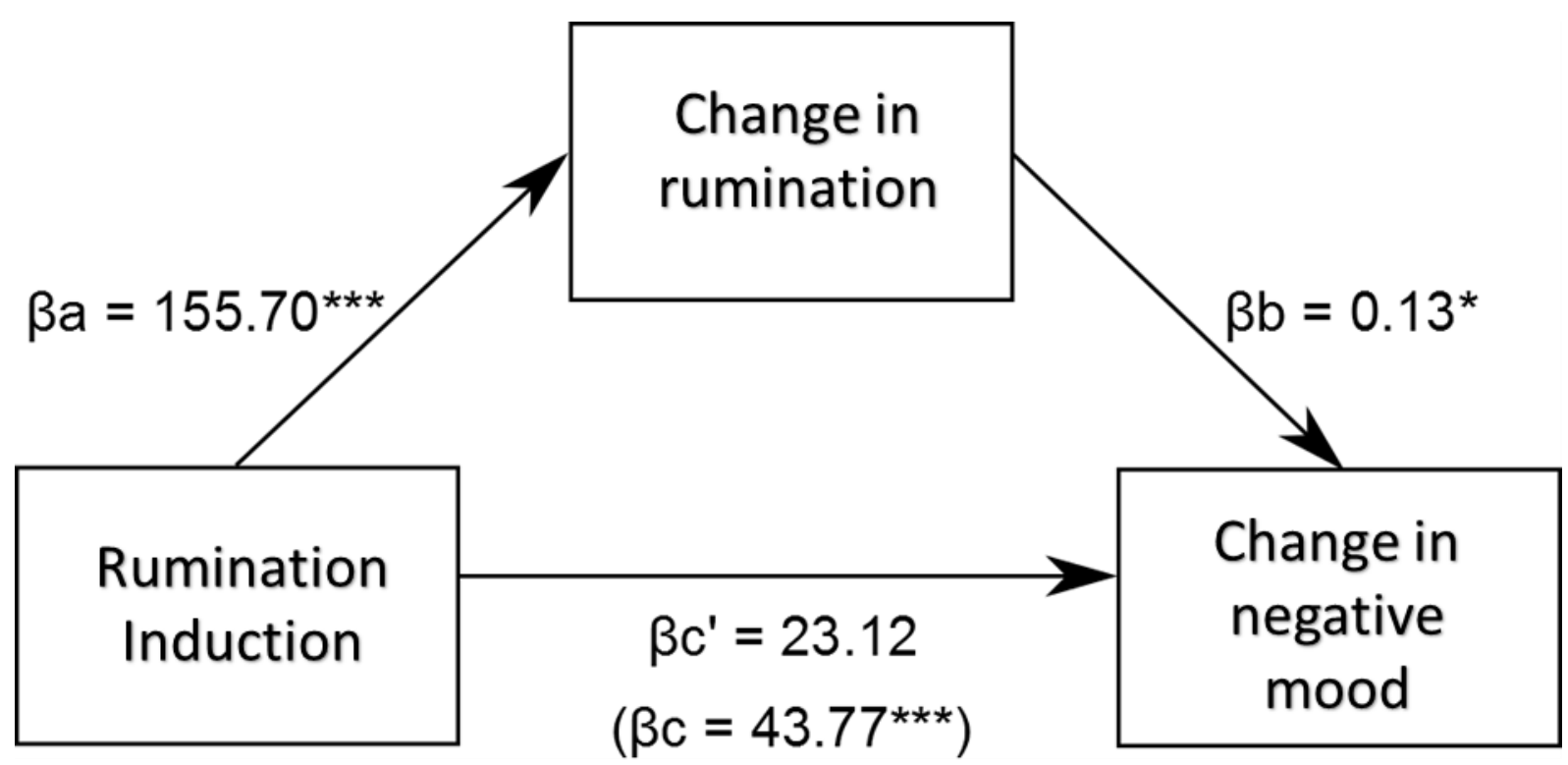

